\title{
Neural Correlates of Performance Monitoring in Daily and Intermittent Smokers
}

\author{
OIga Rass ${ }^{a}$, Daniel J. Fridberg ${ }^{b}$, and Brian F. O'Donnell ${ }^{b, c}$ \\ aDepartment of Psychiatry and Behavioral Sciences, Johns Hopkins University School of \\ Medicine, 5510 Nathan Shock Drive, Baltimore, MD 21224, USA \\ ${ }^{b}$ Department of Psychological and Brain Sciences, Indiana University, 1101 East $10^{\text {th }}$ Street, \\ Bloomington, IN, 47405, USA \\ 'Department of Psychiatry, Indiana University School of Medicine, 340 West 10th Street, Suite \\ 6200, Indianapolis, IN 46202, USA
}

\begin{abstract}
OBJECTIVES-Despite efforts that have increased smoking regulation, cigarette taxation, and social stigma, cigarette smoking remains the leading cause of preventable death worldwide, and a significant personal and public economic burden. In the U.S., intermittent smokers comprise approximately $20 \%$ of all smokers and represent a stable, non-dependent group that may possess protective factors that prevent the transition to dependence. One possibility is that intermittent smokers have intact CNS frontal regulatory and control mechanisms that enable resistance to nicotine-induced changes.
\end{abstract}

METHODS-The present study measured inhibitory control using a flanker task and a go-nogo continuous performance tasks in daily dependent smokers, intermittent non-dependent smokers, and nonsmokers. Event-related potential (ERP) measures of were concurrently recorded to measure performance monitoring via event-related negativity (ERN) and error positivity (Pe) components during error trials for each task.

RESULTS-In both tasks, behavioral and ERN measures did not differ between groups; however, amplitude of the Pe component was largest among intermittent smokers.

CONCLUSIONS-Thus, intermittent smokers differed from both daily smokers and nonsmokers on error processing, potentially revealing neuroprotective cognitive processes in nicotine dependence.

(C) 2013 International Federation of Clinical Neurophysiology. Published by Elsevier Ireland Ltd. All rights reserved

Address correspondence to: Olga Rass Behavioral Pharmacology Research Unit Johns Hopkins University School of Medicine 5510 Nathan Shock Drive Baltimore, MD 21224 Tel: 410-550-7923; Fax: 410-550-0030.

(orass1@jhmi.edu)

(dfridber@indiana.edu)

(bodonnel@indiana.edu)

Publisher's Disclaimer: This is a PDF file of an unedited manuscript that has been accepted for publication. As a service to our customers we are providing this early version of the manuscript. The manuscript will undergo copyediting, typesetting, and review of the resulting proof before it is published in its final citable form. Please note that during the production process errors may be discovered which could affect the content, and all legal disclaimers that apply to the journal pertain. 
SIGNIFICANCE-A better understanding of factors that mediate behavioral regulation may provide novel treatment approaches that help individuals achieve controlled smoking or cessation.

\section{Keywords}

Performance Monitoring; Error-Related Negativity; Event-Related Potentials; Smoking; Substance Dependence

\section{INTRODUCTION}

Difficulty regulating behavior and monitoring performance outcomes plays a significant role in the development and maintenance of addiction (Chiu et al., 2008; de Wit, 2008, Sokhadze et al., 2008). Drug dependent individuals have difficulty inhibiting the response to drugs or drug cues, especially during withdrawal ( $\mathrm{Li}$ and Sinha, 2008). A compromised selfregulatory system in dependent smokers may drive relapse rates to be as high as $50 \%$ in the first week and $95 \%$ in the first year following cessation, despite a desire to quit by nearly $70 \%$ of individuals (CDC, 2011a; Hughes, 2007). Smokers report reduced self-control, increased impulsiveness, and inability to resist temptation, all of which may contribute to relapse (Coggins et al., 2009). Impairments on laboratory tasks of inhibitory control and executive function are evident in abstinent states, even following three months of cessation, compared to satiated states, which may contribute to failed cessation efforts (Billieux et al., 2010; Dawkins et al., 2009; Harrison et al., 2009). Compared to nonsmokers, imaging studies show neuroadaptation of frontostriatal brain regions involved in regulating inhibitory control, as evidenced by reduced frontal grey matter volumes and densities, increases in neural response to drug cues, and reduced anterior cingulate metabolic activity in chronic smokers during abstinence (Feil et al., 2010). The ability to regulate cognitive processes and adjust behavior for optimal performance requires online monitoring of actions and subsequent outcomes (Ridderinkhof et al., 2004). In smokers, reduced neural response following error commission suggests potential difficulties in performance monitoring that may potentiate relapse or continued smoking despite negative health consequences (Franken et al., 2010; Luijten et al., 2011b).

A subset of smokers report feeling in control of their smoking behavior, an absence of withdrawal symptoms, and higher cessation rates (Coggins, 2009; Shiffman, 1989; Shiffman et al., 1990). These self-reported "some day" smokers, also referred to as "chippers" or intermittent smokers (ITS), comprise 22\% (9.9 million) of the U.S. smoking population and this number is believed to be increasing (CDC, 2011b; Shiffman et al., 2012). Their ability to avoid dependence cannot be attributed to differences in smoking topography (e.g., number of puffs, puff duration, inter-puff/cigarette interval) or changes in blood-nicotine concentration (Brauer et al., 1996; Coggins et al., 2009; Shiffman, 1989). Compared to daily, dependent smokers, long-term ITS report having an internal locus of control and greater self-control compared to regular smokers (Coggins, 2009; Kassel et al., 1994; Shiffman and Paty, 2006). Surprisingly, the neurocognitive factors that allow ITS to avoid dependence have received remarkably little attention. 
Behavioral measures of inhibitory control have not been investigated previously in ITS. The Eriksen Flanker Task targets selective inhibition and conflict control, where participants must respond quickly to identify the middle letter (or arrow) in trials when it is flanked by congruent or incongruent letters (or arrows). The Go/No-go continuous performance task targets sustained attention and behavioral control where participants must inhibit a prepotent motor response to a frequently occurring "Go" stimulus when an infrequent 'No-go' stimulus is presented. These tasks reflect the ability to control behavior prior to motor initiation, such as inhibiting smoking-related cues, or the automaticity of reaching for a cigarette when it is available, respectively, and may be especially relevant in the planning and single instances of drug seeking or use. Overall, studies of inhibitory control in smokers have produced mixed results, finding that smokers had impaired accuracy in some (Luijten et al., 2011a: Go/No-go task) but not all studies (Dinn et al., 2004): Go/No-go task, Stroop Color-Word task; Franken, 2010: Flanker task; Luijten, 2011b: modified Flanker task). Impaired performance on measures sensitive to behavioral control, such as the Stop Signal task (Bilieux, 2010) and the Go/No-go and Anti-saccade tasks (Spinella, 2002) has been found to correlate with increased smoking rate and dependence.

The medial frontal cortex and associated regions are involved in monitoring unfavorable outcomes, response errors and conflict, and decision uncertainty (Ridderinkhof et al., 2004). Event-related potential (ERP) recordings during performance of the inhibitory control tasks provide an evaluation of online performance monitoring and behavioral modification when errors are detected. The Error-Related Negativity (ERN) and Error Positivity (Pe) ERP components are believed to index performance monitoring in tasks that induce cognitive and response conflicts. The ERN is a negative-voltage potential with a fronto-central scalp distribution that occurs approximately $50-100 \mathrm{~ms}$ following the commission of an error (Gehring et al., 1993). The Pe is a positive-voltage potential with a fronto-central or centroparietal scalp distribution that occurs approximately $200-400 \mathrm{~ms}$ following an erroneous response (Arbel and Donchin, 2009; Overbeek, 2005). The ERN is associated with automatic error detention or conflict monitoring, whereas the Pe is associated with the awareness and motivational significance of an error (Arbel and Donchin, 2009; Falkenstein et al., 2000; Gehring et al., 2012; Nieuwenhuis et al., 2001; Overbeek et al., 2005; Pontifex et al., 2010; Shalgi et al., 2009; Yeung et al., 2004). Generation of the ERN has been localized to the dorsal anterior cingulate cortex (ACC) with potential contributions from the pre-supplementary motor area and the lateral prefrontal cortex, whereas the less-understood Pe may be comprised of a fronto-central waveform originating from the medial frontal cortex and a late centro-parietal waveform generated by the superior parietal cortex and rostral ACC (Arbel \& Donchin, 2009; Gehring et al., 2012; Herrmann et al., 2004; Overbeek et al., 2005; Pontifex et al., 2010). Recent studies support that the Pe co-varies with the stimulus-locked P300 ERP, associated with attentional salience and novelty detection (Polich, 2007; Ridderinkhof, Ramautar, \& Wijnen, 2009; Shalgi et al., 2009).

Ascending dopaminergic projections, which densely innervate the medial frontal cortex, release the primary neurotransmitter responding to errors in reward prediction. Phasic dopamine changes may play a role in adjusting behavior to improve task performance via reinforcement learning principles (Overbeek et al., 2005). The ERN has been consistently found to be sensitive to dopamine neurotransmission, however the role of dopamine has 
been less certain for the P3-and Pe response (Gehring et al., 2012; Overbeek et al., 2005). There has been some support of dopaminergic mediation of frontal P300 (P3a), but studies have found no influence of dopamine on the Pe response (Gehring et al., 2012; Overbeek et al., 2005; Polich and Criado, 2006). In substance dependence, frontostriatal dysregulation can impair the selection and maintenance of task/goal-relevant information while suppressing inappropriate responses or representations (Dawkins et al., 2009; Feil et al., 2010). Specifically, substance dependence is associated with impairments in the dorsolateral prefrontal cortex (involved in attention, goal identification, and selection) and the ACC (involved in assessment of consequences and error detection) (Feil et al., 2010; Goldstein \& Volkow, 2002), which may contribute to deficits in inhibitory control and performance monitoring.

Imaging studies support that substance abuse populations have shown decreased errorrelated activity in the anterior cingulate cortex, a region believed to be involved in ERN and Pe generation (Gehring, 2012; Olvet and Hajcak, 2008). Studies of drug users have found disrupted ERN response in regular users cocaine (Franken et al., 2007), and alcohol (Schellekens et al., 2010) and disrupted Pe/P300 in users cannabis (Fridberg et al., 2013), cocaine (Franken et al., 2007), and alcohol (Polich \& Ochoa, 2004; Rodriguez Holguin et al., 1999). Fridberg et al. (2013) found no ERN differences between controls and chronic cannabis users. In participants at risk for alcoholism, smoking was found to moderate the P300 such that smoking accounted for more variance of the decreased P300 than alcohol risk (Polich \& Ochoa, 2004). Studies specific to smoking have found reduced amplitudes of the ERN (Luijten et al., 2011b) and Pe (Franken, 2010; Luijten, 2011b) in smokers compared to nonsmokers during inhibitory control tasks (Franken, 2010; Luijten, 2011b). However, Franken et al. (2010) found no ERN differences between controls cigarette smokers. In an oddball task, increased P3a amplitude in response to the distractor shows that the P300 is sensitive to acute nicotine administration both in low-use and high-use chronic smokers, suggesting nicotine-dependent alterations in the brain mechanisms contributing to P300 generation (Polich and Criado, 2006). Finally, acute abstinence from smoking resulted in reduced ERN amplitude during a flanker task (Schlienz et al., 2013). Insensitivity to error commission and suboptimal error detection and processing may contribute to the continuation of maladaptive behaviors despite negative consequences.

Understanding the factors contributing to resistance against nicotine dependence, specifically the ability to control behavior, is crucial for resolving why certain individuals have the ability to control their smoking behavior and for developing more successful prevention and intervention strategies for those who are unable to quit smoking. The purpose of this study is to evaluate whether ITS demonstrate better inhibitory control than dependent smokers as measured by behavioral and ERP measures. We expected that smokers would commit more commission errors (false positives) and exhibit faster reaction times (RTs) than ITS and nonsmokers during inhibitory control tasks, reflecting greater behavioral disinhibition. We expected that ITS would fall between smokers and nonsmokers in terms of those measures. Similarly, amplitudes of performance monitoring ERPs (ERN and $\mathrm{Pe}$ ) were expected to be greatest in nonsmokers, intermediate in ITS, and smallest in dependent smokers. Overall, reduced inhibitory control and error processing deficits were predicted to be associated with increased dependence. 


\section{MATERIALS AND METHODS}

\section{Participants}

Thirty nonsmokers, 31 intermittent smokers (ITS), and 22 daily smokers (DS) were recruited from the local community and paid $\$ 10$ per hour for participation. Participants were excluded for a history of electroconvulsive therapy, neurological illness, or drug dependence based on DSM-IV criteria. Participants were also excluded for current anxiety disorders or major depression, use of psychotropic medications, or current drug abuse. Males drinking more than 14 drinks per week and females drinking more than 7 drinks per week were also excluded. Participants who reported using marijuana more than once per week were excluded. Minimum age for participation was 20 years old to allow for sufficient time for progression to nicotine dependence (Brook et al., 2010; Dierker et al., 2008). Maximum participation age was 50 years old. All participants received detailed information about the study protocol and gave written and oral informed consent. The local institutional review board approved the study.

Groups were classified according to the following criteria. Nonsmokers smoked $<10$ cigarettes in their lifetime and had not smoked in the past month. ITS 1) in the preceding 90 days, smoked on $\geq 10$ days or smoked $\geq 20$ cigarettes; 2 ) smoked $<27$ days per month for the preceding six months; 3 ) were not attempting to quit; 4) smoked in any capacity for the previous three years; and 5) scored <4 on the Fagerström Test for Nicotine Dependence (FTND) (Baker et al., 2007; Heatherton et al., 1991). DS 1) smoked <25 cigarettes per day, daily for $\geq 12$ months; and 2) scored $\geq 4$ on the FTND. Demographic information for the three groups is presented in Table 1 .

\section{Procedure}

Interviews-Potential participants were screened by phone to determine their eligibility for the study. Study eligibility was confirmed in the laboratory using the demographics and screening module of the Structured Clinical Interview for Axis-I disorders (SCID-I; First et al., 1997), with follow-up questions from additional modules when necessary.

Smoking Behavior and $\mathrm{CO}$ levels-Questionnaires were mailed to individuals who qualified for the study and were completed prior to or after the lab session. Nicotine dependence was assessed using the Fagerström Test for Nicotine Dependence (FTND; Heatherton, 1991) and the Nicotine Dependence Syndrome Scale (NDSS; Shiffman et al., 2004). Nicotine dependence was defined as a score $\geq 4$ on the FTND (Baker, 2007). Current nicotine withdrawal was assessed before and after the three-hour testing session using a revised Wisconsin Smoking Withdrawal Scale (WSWS; Hendricks et al., 2006). Breath carbon monoxide (CO) was measured before and after the testing session (piCO+, Bedfont Scientific Ltd., Rochester, UK). A criterion of six to eight CO ppm differentiates smokers from nonsmokers (Pearce and Hayes, 2005). Smoking measures are presented in Table 1.

Inhibitory Control Tasks-The Eriksen Flanker Task is designed to assess selective inhibition of distracting information and attentional control (Eriksen and Eriksen, 1974). In the version used in the present study, participants identified the middle letter of five letters 
presented on the computer screen. Participants were told that their goal was to respond quickly and accurately to each trial. Figure 1 is a schematic of the events occurring on each trial. Following a block of 20 practice trials, participants completed four blocks of 100 trials, with a rest period provided after every block. Congruent and incongruent trials were presented at an equal rate and trials were randomized within each block. The computer recorded accuracy and RTs for each trial. The Go/No-go Continuous Performance Task is designed to measure sustained attention and behavioral response inhibition (Fridberg et al., 2013). In this Go/No-go version, participants made a two-choice discrimination between "X" and "O" stimuli that were rapidly presented on the computer screen. Stimuli were counterbalanced for presentation rates of rare (20\%) or frequent $(80 \%)$. Participants were instructed to respond quickly and accurately to each trial. Figure 1 is a schematic of the events occurring on each trial. Participants completed 30 practice trials where the stimuli were presented at an equal rate, followed by four blocks of 125 experimental trials. Trials were randomized within each block, and rest periods were provided after every block. The computer recorded accuracy and RTs for each trial.

Electrophysiological Assessment-The electroencephalogram was sampled continuously ( $1000 \mathrm{~Hz}$ sampling rate, $0.1-200 \mathrm{~Hz}$ bandpass filter) from $34 \mathrm{Ag} / \mathrm{AgCl}$ electrodes mounted in a cap (EasyCap, $\mathrm{GmbH}$ ) and referenced to the nose (Torpey et al., 2012; Wiswede et al., 2009; Zirnheld et al., 2004). Two Ag/AgCl electrodes placed above and below the participant's left eye recorded bipolar vertical electrooculogram (vEOG). Neuroscan SynAmps I digitized the EEG, and electrode impedances were maintained at $<10$ $\mathrm{kOhm}$. Participants completed the EEG recording session while comfortably seated in a sound-attenuated room. The Flanker and Go/No-go task order was randomized across participants. Stimuli were presented on a Power Macintosh computer using SuperLab stimulus presentation software. Stimuli were presented on a 17-inch CRT monitor centered $70 \mathrm{~cm}$ away from the participants.

For offline processing, the EEG was segmented into $1000 \mathrm{~ms}$ epochs, including a $200 \mathrm{~ms}$ pre-response baseline using Brain Vision Analyzer software (Brain Products, GmbH). The data were baseline corrected and filtered using a $0.1-40 \mathrm{~Hz}$ ( $24 \mathrm{~dB} /$ octave roll-off) using a Butterworth filter. Epochs were corrected for ocular artifacts using the Gratton et al. (1983) algorithm. Epochs with voltage exceeding $\pm 100 \mu \mathrm{V}$ at any site were automatically excluded from further analyses. Participants with fewer than ten accepted error trials were excluded from analysis (Olvet and Hajcak, 2009). Insufficient trials after artifact rejection resulted in the exclusion of four nonsmokers, five ITS, and one DS from Flanker analysis and four nonsmokers, two ITS, and one DS from Go/No-go analysis. The number of segments accepted for signal processing did not differ significantly between groups for Flanker task or Go/No-go task (Table 2).

Data Analysis: One-way Analysis of Variance (ANOVA) with between-subjects factor of group (3) was run for every self-report dependent variable. Although nonsmokers were more educated than DS (Table 1), years of education was not a significant covariate for any dependent measure when included in analysis of covariance (ANCOVA), and was therefore not included in the analysis. For the Flanker and Go/No-go behavioral data, group error rates 
and post-error slowing were compared using ANOVA. Post-error slowing was calculated as the mean RT for post-error correct trials minus the mean RT for pre-error correct trials (Dutilh et al., 2012). In addition, accuracy and RTs were compared using a 3 (Group) $\times 2$ (Stimulus Type: Congruent or Incongruent for Flanker, Frequent or Rare for Go/No-go) repeated-measures ANOVA. Follow-up ANOVAs and post-hoc Fisher's Least Significant Difference (LSD) test were used to resolve significant main effects or interactions for posthoc analysis. Greenhouse-Geisser corrections for nonsphericity were applied when appropriate. One ITS did not complete the Flanker task and the Go/No-go task due to computer malfunction. Data from two nonsmokers were excluded from analysis due to commission of only one error and performance at chance levels.

For EEG data analysis, response-locked ERP averages were constructed using error trials for each participant, and did not include trials when the participant did not respond. The ERN and Pe components were measured at midline electrode sites (Fz, FCz, Cz, CPz, and Pz) based on previous research (Overbeek, 2005; Torpey, 2012). The ERN was automatically detected as the maximally negative voltage between 50 before to $100 \mathrm{~ms}$ after the incorrect response, and the Pe was automatically detected as the maximum positive voltage between 100 and $250 \mathrm{~ms}$ after the incorrect response. Peak amplitude was measured as the mean of the maximal voltage and its surrounding 20 data points (i.e., maximal value \pm 10 data points). Because the ERN was maximal at $\mathrm{FCz}$ and the Pe was maximal at $\mathrm{Cz}$ for both tasks across the entire participant sample, group comparisons focused on latency and amplitude at these sites. ANOVA was used to determine group differences and Greenhouse-Geisser corrections were applied when appropriate. Effect size estimates for analysis of variance were determined with partial $\eta 2$ (partial $\eta 2=.01$ is a small effect size, .06 is a medium effect size, and .14 is large effect size) (Kittler et al, 2007). Data from one nonsmoker were excluded from analysis in the Flanker task for having an ERN voltage value differ from other participants by more than four standard deviations.

\section{RESULTS}

\section{Behavioral Outcomes}

Eriksen Flanker Task-For the assessment of accurate RTs, a group (3) $\times$ condition (2: congruent, incongruent) repeated measures ANOVA found faster RTs in the congruent condition $(F[1,77]=271.83, p<.001)$ (Table 3$)$. There was no main effect of group $(F[2,77]=$. $90)$ and no group $\times$ condition interaction $(F[2,77]=.81)$. For the assessment of error commission, a group (3) $\times$ condition $(2)$ repeated measures ANOVA found more errors in the incongruent condition $(F[1,77]=149.02, p<.001)$. There was no main effect of group $(F[2,77]=.27)$ and no group $\times$ condition interaction $(F(2,77)=.976)$. Finally, no group differences were found for post-error slowing $(F[2,77]=1.01, p=.368)$.

Go/No-go Continuous Performance Task-For the assessment of accurate RTs on the Go/No-go task, a group (3) $\times$ condition (2: frequent, rare) repeated measures ANOVA found faster RTs in the frequent condition $(F[1,79]=323.98, p<.001)$ (Table 3$)$. There was no main effect of group $(F[2,79]=1.00)$ and no group $\times$ condition interaction $(F[2,79]=.51)$. For the assessment of errors, a group (3) $\times$ condition (2) repeated measures ANOVA found more 
errors in the rare condition $(F[1,79]=231.66, p<.001)$. There was no main effect of group $(F[2,79]=.08)$ and no group $\times$ condition interaction $(F[2,79]=.51)$. Finally, no group differences were found for post-error slowing.

\section{Electrophysiological Measures}

ERP outcomes are presented in Table 2. Figures 2-4 illustrate the grand averaged waveforms recorded during error trials of the Flanker and Go/No-go tasks. Figure 5 illustrates ERN and Pe component magnitudes calculated from the waveforms.

Eriksen Flanker Task-ANOVA revealed that ERN amplitude did not differ among groups. ERN latency was earlier for DS than ITS ( $p=.007)$. A trend for significant group effect for Pe amplitude ( $p=.052$ ), with ITS having the highest response. No Pe latency differences were found.

Go/No-go Continuous Performance Task-ANOVA revealed that ERN amplitude and latency did not differ among groups. A main effect of group for PE amplitude revealed a greater amplitude for ITS compared to daily smokers $(p=.017)$ and showed a trend for greater amplitude than nonsmokers $(p=.051)$. No Pe latency differences were found.

\section{DISCUSSION}

The present study measured behavioral and electrophysiological indices of inhibitory control and performance monitoring in daily smokers, intermittent smokers (ITS), and nonsmokers. Daily smokers endorsed greater smoking rates and motivation, nicotine dependence, and risk factors for smoking than ITS. Groups did not differ in performance on the Flanker and Go/No-go task. Although we predicted that ERP amplitudes would decrease in magnitude as a mirror of smoking dependence, from none (high amplitude) to dependent (low amplitude), we found an absence of group differences for the ERN indicating that nicotine dependence alone is not responsible for deficits in executive control mechanisms. Furthermore, the amplitude of the error positivity (Pe) event-related potential was greatest among ITS during both inhibitory control tasks, indicating neural differences unique to ITS. Finally, faster ERN latency in DS may reflect acute nicotine effects.

The increased Pe component in ITS compared to daily smokers is intriguing in light of the absence of behavioral differences on the cognitive measures. The functional significance of the Pe is unclear and has not been well established in the context of drug abuse and dependence. Pe has been associated with conscious error processing and the motivational salience of an event (Falkenstein, 2000; Overbeek, 2005). Based on these interpretations of the Pe, ITS may have an increased sensitivity to error commission compared with both DS and nonsmokers. The increased response following error commission may indicate subsequent activation of executive functioning, reflecting heightened performance monitoring or greater sensitivity in circuitry that is also used to regulate smoking behavior. The Pe in nonsmokers may represent typical, or compared to ITS under-practiced performance monitoring, whereas monitoring in DS may be supplemented by the acute nicotine state.

Clin Neurophysiol. Author manuscript; available in PMC 2015 July 01. 
A study of chronic cannabis users also found increased Pe ERPs and faster RTs for both correct and incorrect trials on the Go/No-go task relative to cannabis-naïve participants (Fridberg et al., 2013). The neural and reaction time differences were interpreted as a compensatory response following error commission. In the present study, a lack of behavioral differences among groups makes it difficult to provide evidence for a similar mechanism. However, it is important to note that cannabis use may reflect intermittent or non-dependent drug use behavior. Estimates of cannabis use in the U.S. population report high lifetime (42\%) and past year (12\%) prevalence, however the prevalence of abuse and dependence in ever users is low (9\%) compared to other illicit drugs (e.g., nicotine conditional dependence: 40\%) (Anthony et al., 1994; SAMHSA, 2010). Only 30\% of chronic users in the Fridberg et al. (2013) study met DSM-IV criteria for dependence. Successful performance monitoring and regulatory behaviors may be associated with controlled drug use behavior and adaptive neural activation during error trials. Future studies are needed to examine individual differences in the Pe ERPs in individuals with chronic, non-dependent drug use.

The present results are consistent with those of previous studies that have found small or no differences between smokers and nonsmokers on inhibitory control tasks. In a Go/No-go task using picture stimuli, Luitjen et al. (2011a) found a trend for decreased accuracy on Nogo trials in smokers compared to nonsmokers and no differences for RTs. Luitjen et al. (2011b) found no accuracy differences in a Flanker task that included pictures, though nonsmokers had increased post-error slowing following an error response, suggesting better performance monitoring. Franken et al. (2010) also found no accuracy or response time differences in a standard Flanker task. Smoking status, rate, and dependence correlated with poor performance on several behavioral inhibition tasks, including Go/No-go, anti-saccades, and delayed alteration task (Billieux, 2010; Spinella, 2002). It is possible that increased task difficulty and smoking rate/dependence may increase group differences due to recruitment of additional resources and greater engagement of control mechanisms.

ERP measures of performance monitoring have seldom been assessed in substance abuse/ dependence populations, especially in smokers. Similar to the present study, Franken et al. (2010) found no ERN differences between smokers and nonsmokers on an Eriksen Flanker task. Luitjen et al. (2011b) suggest that the absence of ERN differences in the Franken et al. (2010) study was due to a lack of challenge and included smoking images during the Flanker task. The error rate in the current study was higher (11\%) than the Luitjen et al. (2011b) rate $(\approx 6.2 \%)$ for incongruent trials, and error rates did not differ across groups for either study. Although the smoking picture condition did not increase error rates compared to the neutral picture condition, Luitjen et al. (2011b) found ERN reductions for smokers compared to nonsmokers. Increasing task difficulty by requiring divided attention may have reduced available cognitive resources in smokers, resulting in reduced ERN compared to nonsmokers. Additionally, both Franken et al. (2010) and Luitjen et al. (2011b) found a reduced Pe for smokers compared to nonsmokers. Although their participants were similar to those in the present study in terms of nicotine dependence, absence of psychopathology, and other drug dependence, they were younger and they used both hands to respond, which may have required greater response control. An absence of ERN or Pe differences between 
dependent smokers and nonsmokers in the present study was further supported by the fact that no differences were found in two separate tasks, the Flanker and Go/No-go.

\section{Limitations and Future Directions}

The comparison of satiated DS to ITS and nonsmokers in the present study was intended to avoid comparing a withdrawal state in DS to groups who do not experience withdrawal (ITS) or do not smoke. As a result, acute nicotine effects in DS may explain the lack of behavioral or electrophysiological differences when compared to nonsmokers. However, acute effects were not present in ITS who had increased Pe response that may be independent of nicotine state. Future studies are needed to test DS and ITS in peak and trough nicotinic states to resolve nicotine effects on ERPs in dependent and non-dependent individuals. A recent study found that response inhibition training in heavy drinkers resulted in reduced weekly alcohol intake (Houben et al., 2011). Therefore, the ability to monitor and exert control over behavior may be instrumental in achieving more-controlled smoking behavior or remission. Future studies are needed to investigate the ability to train ITS and DS in performance monitoring across different smoking and emotional/stress states as well as evaluate performance monitoring in long-term non-dependent substance to determine if the ERN or Pe are useful endophenotypes in substance dependence and its treatment.

There are additional limitations to the present study that should be considered. The participants' young age (Median=23) limits generalizability to older smokers with longer durations of smoking, who may demonstrate more pronounced neurobehavioral effects. Furthermore, only two daily smokers smoked more than a pack per day ( $n \approx 25$ cigarettes), suggesting that this sample may be comprised primarily of relatively light to moderate smokers. In order to investigate differences due to nicotine alone, participation criteria excluded smokers with comorbid psychiatric disorders, which commonly occur in smokers. A larger sample size and greater variability in smoking history, comorbid diagnoses, gender, and ethnicity would the address these limitations.

\section{Conclusions}

A larger Pe response in ITS may be suggestive of higher responsiveness to error and may be associated with better performance monitoring. Differences in error processing could be used as risk factors in nicotine dependence, applied to evaluations of smoking cessation efficacy, and provide a deeper understanding of addiction processes in the brain.

\section{Acknowledgments}

This work was supported by NIDA T32 DA024628, NIDA T32 AA007462-26, Indiana University, and the McNair Scholars Program Grant from the U.S. Department of Education Grant \# P217A80085. We thank Tara Davis and Amy Zhang for their assistance with collecting the data presented in this report.

\section{REFERENCES}

Anthony JC, Warner LA, Kessler RC. Comparative epidemiology of dependence on tobacco, alcohol, controlled substances, and inhalants: Basic findings from the national comorbidity survey. Exp Clin Psychopharmacol. 1994; 2:244-268.

Arbel Y, Donchin E. Parsing the componential structure of post-error ERPs: a principal component analysis of ERPs following errors. Psychophysiology. 2009; 46:1179-1189. [PubMed: 19659694] 
Baker TB, Piper ME, McCarthy DE, Bolt DM, Smith SS, Kim SY, et al. Time to first cigarette in the morning as an index of ability to quit smoking: implications for nicotine dependence. Nicotine Tob Res. 2007; 9(Suppl 4):S555-570. [PubMed: 18067032]

Billieux J, Gay P, Rochat L, Khazaal Y, Zullino D, Van der Linden M. Lack of inhibitory control predicts cigarette smoking dependence: evidence from a non-deprived sample of light to moderate smokers. Drug Alcohol Depend. 2010; 112:164-167. [PubMed: 20667667]

Brook DW, Zhang C, Brook JS, Finch SJ. Trajectories of cigarette smoking from adolescence to young adulthood as predictors of obesity in the mid-30s. Nicotine Tob Res. 2010; 12:263-270. [PubMed: 20083648]

Centers for Disease Control and Prevention. Quitting Smoking Among Adults-United States, 20012010. Morbidity and Mortality Weekly Report. 2011a; 60:1513-1519. [PubMed: 22071589]

Centers for Disease Control and Prevention. Vital Signs: Current Cigarette Smoking Among Adults Aged 18 Years - United States, 2005-2010. Morbidity and Mortality Weekly Report. 2011b; 60:1207-1212. [PubMed: 21900875]

Chiu PH, Lohrenz TM, Montague PR. Smokers' brains compute, but ignore, a fictive error signal in a sequential investment task. Net Neurosci. 2008; 11:514-520.

Coggins CR, Murrelle EL, Carchman RA, Heidbreder C. Light and intermittent cigarette smokers: a review (1989-2009). Psychopharmacology (Berl). 2009; 207:343-363. [PubMed: 19830407]

Dawkins L, Powell JH, Pickering A, Powell J, West R. Patterns of change in withdrawal symptoms, desire to smoke, reward motivation and response inhibition across 3 months of smoking abstinence. Addiction. 2009; 104:850-858. [PubMed: 19344444]

de Wit H. Impulsivity as a determinant and consequence of drug use: A review of underlying processes. Addict Biol. 2009; 14:22-31. [PubMed: 18855805]

Dierker L, He J, Kalaydjian A, Swendsen J, Degenhardt L, Glantz M, et al. The importance of timing of transitions for risk of regular smoking and nicotine dependence. Ann Behav Med. 2008; 36:8792. [PubMed: 18704617]

Dinn WM, Aycicegi A, Harris CL. Cigarette smoking in a student sample: neurocognitive and clinical correlates. Addict Behav. 2004; 29:107-126. [PubMed: 14667424]

Dutilh G, Vandekerckhove J, Forstmann BU, Keuleers E, Brysbaert M, Wagenmakers EJ. Testing theories of post-error slowing. Atten Percept Psychophys. 2012; 74:454-465. [PubMed: 22105857]

Eriksen BA, Eriksen CW. Effects of noise letters upon the identification of a target letter in a nonsearch task. Percept Psychophys. 1974; 16:143-149.

Falkenstein M, Hoormann J, Christ S, Hohnsbein J. ERP components on reaction errors and their functional significance: a tutorial. Biol Psychol. 2000; 51:87-107. [PubMed: 10686361]

Feil J, Sheppard D, Fitzgerald PB, Yucel M, Lubman DI, Bradshaw JL. Addiction, compulsive drug seeking, and the role of frontostriatal mechanisms in regulating inhibitory control. Neurosci Biobehav Rev. 2010; 35:248-275. [PubMed: 20223263]

First, MB.; Spitzer, RL.; Gibbon, M.; Williams, JBW. Structured Clinical Interview for DSM-IV Axis I Diosrders - Non-patient Edition (SCID-I/NP, Version 2.0 - 4/97 revision). Biometrics Research Department; New York, NY: 1997.

Franken IH, van Strein JW, Franzek EJ, van de Wetering BJ. Error processing deficits in patients with cocaine dependence. Bio Psychol. 2007; 75:45-51. [PubMed: 17196732]

Franken IH, van Strien JW, Kuijpers I. Evidence for a deficit in the salience attribution to errors in smokers. Drug Alcohol Depend. 2010; 106:181-185. [PubMed: 19781864]

Fridberg DJ, Skosnik PD, Hetrick WP, O'Donnell BF. Neural correlates of performance monitoring in chronic cannabis users and cannabis-naive controls. J Psychopharmacol. 2013; 27:515-525. [PubMed: 23427191]

Gehring WJ, Goss B, Coles MGH, Meyer DE, Donchin E. A Neural System for Error-Detection and Compensation. Psychol Sci. 1993; 4:385-390.

Gehring, WJ.; Liu, Y.; Orr, JM.; Carp, J. The Error Related Negativity (ERN/Ne). In: Luck, SJ.; Kappenman, ES., editors. The oxford handbook of event-related potential components. Oxford University Press; New York, NY: 2012. 
Goldstein RZ, Volkow ND. Drug addiction and its underlying neurobiological basis: Neuroimaging evidence for the involvement of the frontal cortex. Am J Psychiatry. 2002; 159:1642-1652. [PubMed: 12359667]

Gratton G, Coles MG, Donchin E. A new method for off-line removal of ocular artifact. Electroencephalogr Clin Neurophysiol. 1983; 55:468-484. [PubMed: 6187540]

Harrison EL, Coppola S, McKee SA. Nicotine deprivation and trait impulsivity affect smokers' performance on cognitive tasks of inhibition and attention. Exp Clin Psychopharmacol. 2009; 17:91-98. [PubMed: 19331485]

Heatherton TF, Kozlowski LT, Frecker RC, Fagerstrom KO. The Fagerstrom Test for Nicotine Dependence: a revision of the Fagerstrom Tolerance Questionnaire. Br J Addict. 1991; 86:1119_ 1127. [PubMed: 1932883]

Hendricks PS, Ditre JW, Drobes DJ, Brandon TH. The early time course of smoking withdrawal effects. Psychopharmacology (Berl). 2006; 187:385-396. [PubMed: 16752139]

Houben K, Nederkoorn C, Wiers RW, Jansen A. Resisting temptation: decreasing alcohol-related affect and drinking behavior by training response inhibition. Drug Alcohol Depend. 2011; 116:132-136. [PubMed: 21288663]

Hughes JR. Effects of abstinence from tobacco: valid symptoms and time course. Nicotine Tob Res. 2007; 9:315-327. [PubMed: 17365764]

Kassel JD, Shiffman S, Gnys M, Paty J, Zettler-Segal M. Psychosocial and personality differences in chippers and regular smokers. Addict Behav. 1994; 19:565-575. [PubMed: 7832015]

Kittler JH, Menard W, Phillips KA. Weight concerns in individuals with body dysmorphic disorder. Eat Behav. 2007; 8:115-120. [PubMed: 17174859]

Li CR, Sinha R. Inhibitory control and emotional stress regulation: Neuroimaging evidence for frontal -limbic dysfunction in psycho-stimulant addiction. Neurosci Biobehav R. 2008; 32:581-597.

Luijten M, Littel M, Franken IH. Deficits in inhibitory control in smokers during a Go/NoGo task: an investigation using event-related brain potentials. PLoS One. 2011a; 6:e18898. [PubMed: 21526125]

Luijten M, van Meel CS, Franken IH. Diminished error processing in smokers during smoking cue exposure. Pharmacol Biochem Behav. 2011b; 97:514-520. [PubMed: 21047524]

Nieuwenhuis S, Ridderinkhof KR, Blom J, Band GP, Kok A. Error-related brain potentials are differentially related to awareness of response errors: evidence from an antisaccade task. Psychophysiology. 2001; 38:752-760. [PubMed: 11577898]

Olvet DM, Hajcak G. The error-related negativity (ERN) and psychopathology: toward an endophenotype. Clin Psychol Rev. 2008; 28:1343-1354. [PubMed: 18694617]

Olvet DM, Hajcak G. The stability of error-related brain activity with increasing trials. Psychophysiology. 2009; 46:957-961. [PubMed: 19558398]

Overbeek TJM, Nieuwenhuis S, Ridderinkhof KR. Dissociable components of error processing - On the functional significance of the Pe Vis-a-vis the ERN/Ne. J Psychophysiol. 2005; 19:319-329.

Pearce MS, Hayes L. Self-reported smoking status and exhaled carbon monoxide: results from two population-based epidemiologic studies in the North of England. Chest. 2005; 128:1233-1238. [PubMed: 16162711]

Polich J. Updating P300: An integrative theory of P3a and P3b. Clin Neurophysiol. 2007; 118:21282148. [PubMed: 17573239]

Polich J, Criado JR. Neuropsychology and neuropharmacology of P3a and P3b. Int J Psychophysiol. 2006; 60:172-185. [PubMed: 16510201]

Polich J, Ochoa CJ. Alcoholism risk, tobacco smoking, and Pe00 event-related potential. Clin Neurophysiol. 2004; 115:1374-1383. [PubMed: 15134705]

Pontifex MB, Scudder MR, Brown ML, O'Leary KC, Wu CT, Themanson JR, et al. On the number of trials necessary for stabilization of error-related brain activity across the life span. Psychophysiology. 2010; 47:767-773. [PubMed: 20230502]

Ridderinkhof KR, Ramautar JR, Wijnen JG. To P(E) or not to P(E): A P3-like ERP component reflecting the processing of response errors. Psychophysiology. 2009; 46:531-538. [PubMed: 19226310] 
Ridderinkhof KR, Ullsperger M, Crone EA, Nieuwenhuis S. The role of the medial frontal cortex in cognitive control. Science. 2004; 306:443-447. [PubMed: 15486290]

Rodriguez Holguin S, Porjesz B, Chorlian DB, Polich J, Begleiter H. Visual P3a in male alcoholics and controls. Alcohol Clin Exp Res. 1999; 23:582-91. [PubMed: 10235292]

Shalgi S, Barkan I, Deouell LY. On the positive side of error processing: error-awareness positivity revisited. Eur J Neurosci. 2009; 29:1522-1532. [PubMed: 19519632]

Shiffman S. Tobacco "chippers"--individual differences in tobacco dependence. Psychopharmacology (Berl). 1989; 97:539-547. [PubMed: 2498951]

Shiffman S, Fischer LB, Zettler-Segal M, Benowitz NL. Nicotine exposure among nondependent smokers. Arch Gen Psychiatry. 1990; 47:333-336. [PubMed: 2322084]

Shiffman S, Paty J. Smoking patterns and dependence: contrasting chippers and heavy smokers. J Abnorm Psychol. 2006; 115:509-523. [PubMed: 16866591]

Shiffman S, Tindle H, Li X, Scholl S, Dunbar M, Mitchell-Miland C. Characteristics and smoking patterns of intermittent smokers. Exp Clin Psychopharmacol. 2012; 20:264-277. [PubMed: 22390208]

Shiffman S, Waters A, Hickcox M. The nicotine dependence syndrome scale: a multidimensional measure of nicotine dependence. Nicotine Tob Res. 2004; 6:327-348. [PubMed: 15203807]

Spinella M. Correlations between orbitofrontal dysfunction and tobacco smoking. Addict Biol. 2002; 7:381-384. [PubMed: 14578013]

Substance Abuse and Mental Health Services Administration. The National Survey on Drug Use and Health. 2010. Types of illicit drug use in lifetime, past year, and past month among persons aged 12 or older.

Schellekens AF, de Bruijn ER, van Lankveld CA, Hulstijn W, Buitelaar JK, de Jong CA, Verkes RJ. Alcohol dependence and anxiety increase error-related brain activity. Addiction. 2010; 105:11928-1934.

Schlienz NJ, Hawk LW Jr, Rosch KS. The effects of acute abstinence from smoking and performancebased rewards on performance monitoring. Psychopharmacology. 2013; 229:701-711. [PubMed: 23681159]

Sokhadze E, Stewart C, Hollifield M, Tasman A. Event-related potential study of executive dysfunctions in a speeded reaction task in cocaine addiction. J Neurother. 2008; 12:185-204. [PubMed: 19830263]

Torpey DC, Hajcak G, Kim J, Kujawa A, Klein DN. Electrocortical and behavioral measures of response monitoring in young children during a Go/No-Go task. Dev Psychobiol. 2012; 54:139150. [PubMed: 21815136]

U.S. Census Bureau. Profile of general population and housing characteristics: Bloomington, Indiana. 2010. Retrieved from https://bloomingtoningov/media/media/application/pdf/6636pdf2010

Wiswede D, Munte TF, Goschke T, Russeler J. Modulation of the error-related negativity by induction of short-term negative affect. Neuropsychologia. 2009; 47:83-90. [PubMed: 18786553]

Yeung N, Botvinick MM, Cohen JD. The neural basis of error detection: conflict monitoring and the error-related negativity. Psychol Rev. 2004; 111:931-959. [PubMed: 15482068]

Zirnheld PJ, Carroll CA, Kieffaber PD, O'Donnell BF, Shekhar A, Hetrick WP. Haloperidol impairs learning and error-related negativity in humans. J Cogn Neurosci. 2004; 16:1098-1112. [PubMed: 15298795] 


\section{HIGHLIGHTS}

- This is the first study to measure inhibitory control and event-related potentials (ERP) measures of performance monitoring in nondaily, non-dependent smokers.

- Monitoring and regulation of behavior is important for adaptive and optimal performance that is impaired in persons with substance dependence.

- Increased Error Positivity ERP response in nondaily smokers reflects cognitive processes that may prevent the transition to dependent smoking. 

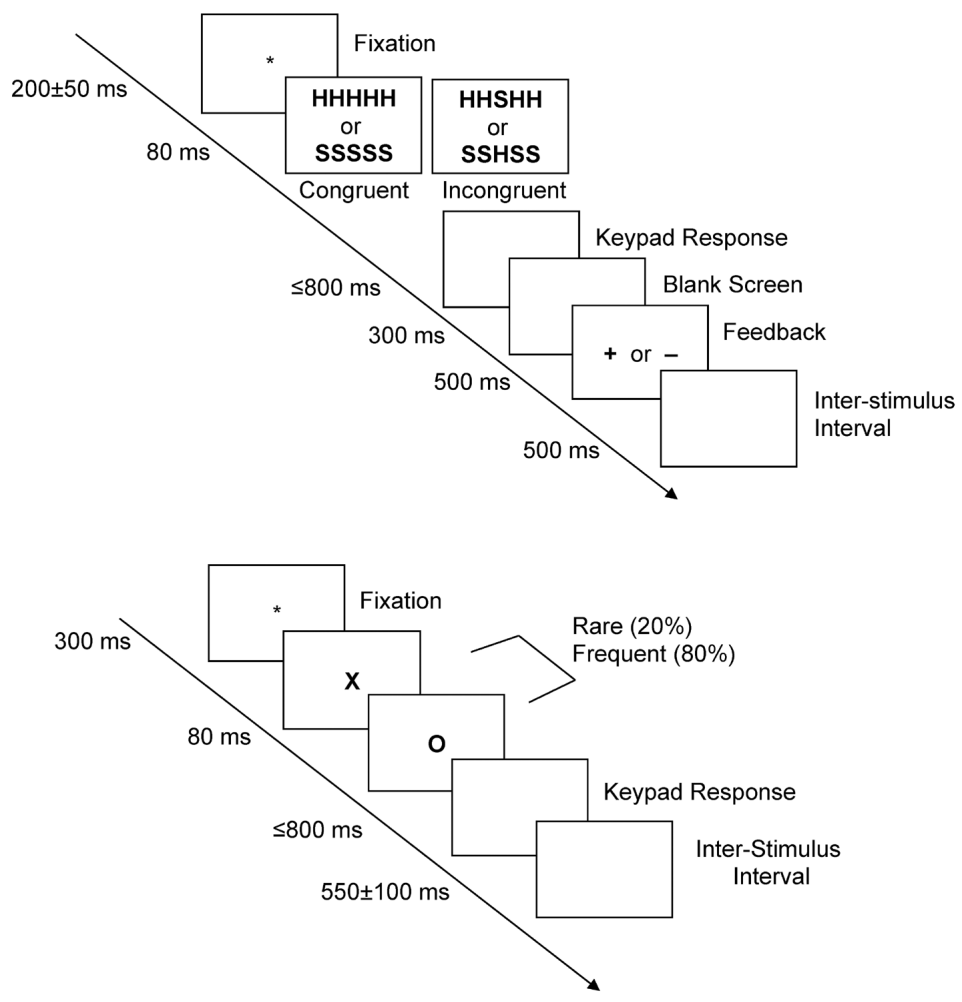

Figure 1.

Schematic of the stimulus display during the Eriksen Flanker Task (A) and Go/No-go Continuous Performance Task (B). For the Flanker Task, each trial began with a fixation asterisk followed by a congruent $(50 \%)$ or incongruent $(50 \%)$ letter string. Participants were allotted $800 \mathrm{~ms}$ for keypress response using dominant hand, after which feedback was presented. For the Go/No-go task, each trial began with a fixation asterisk followed by a letter stimulus. Participants were allotted $800 \mathrm{~ms}$ to respond. No feedback was provided between trials. 

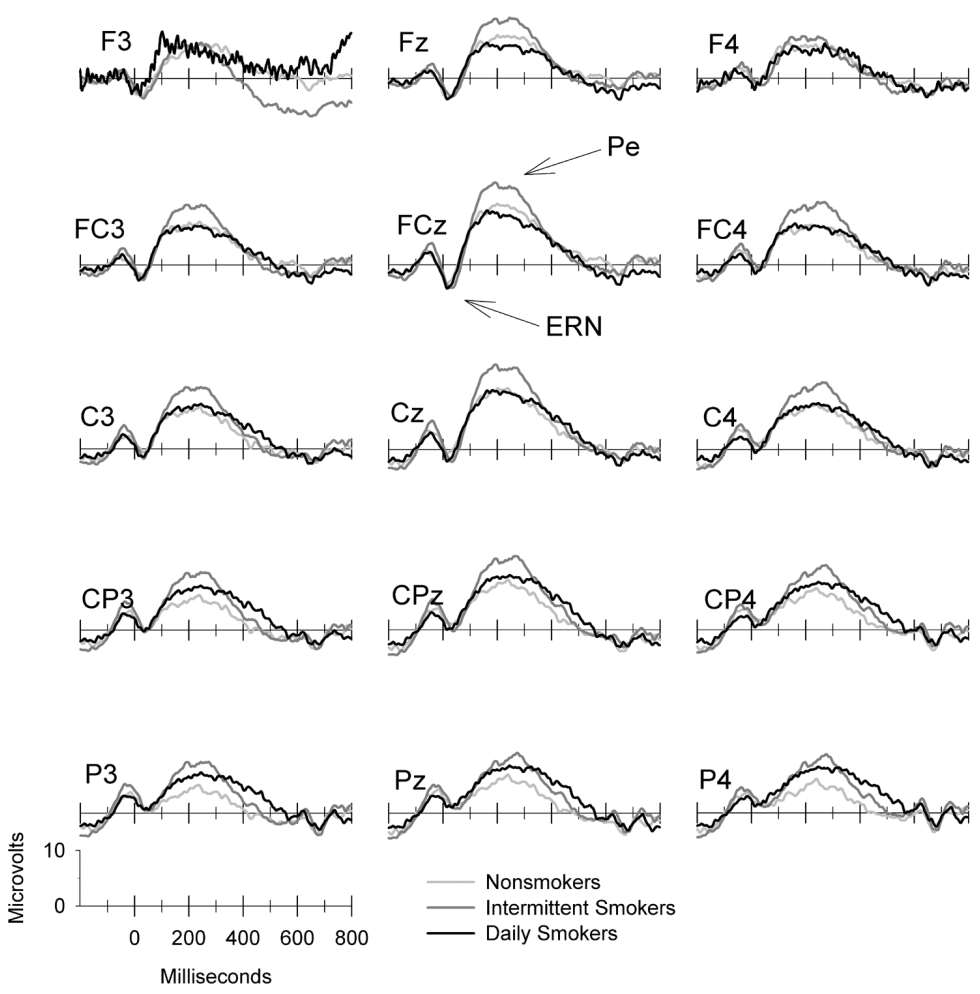

Figure 2.

Response-locked grand average ERP activity during error trials of the Eriksen Flanker Task for nonsmokers (light gray line), intermittent smokers (dark gray line), and daily smokers (black line). 

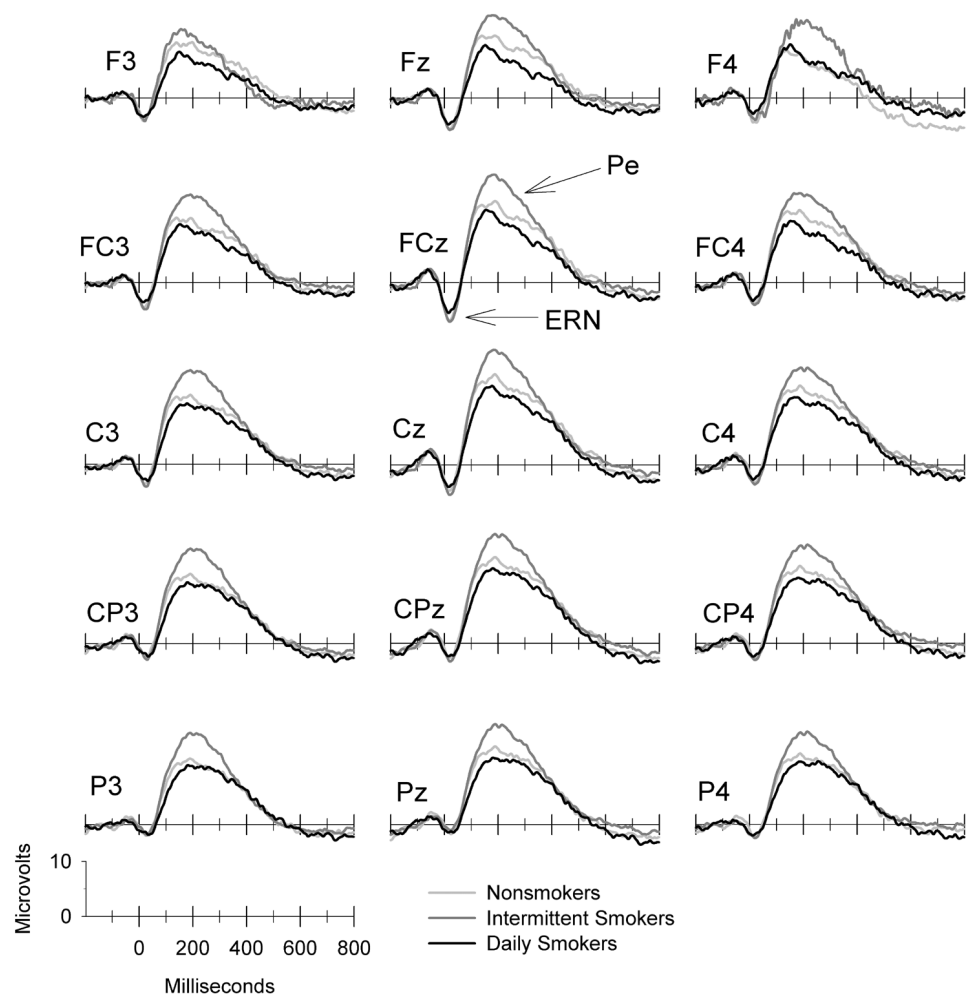

Figure 3.

Response-locked grand average ERP activity during error trials of the Go/No-go Continuous Performance Task for nonsmokers (light gray line), intermittent smokers (dark gray line), and daily smokers (black line). 

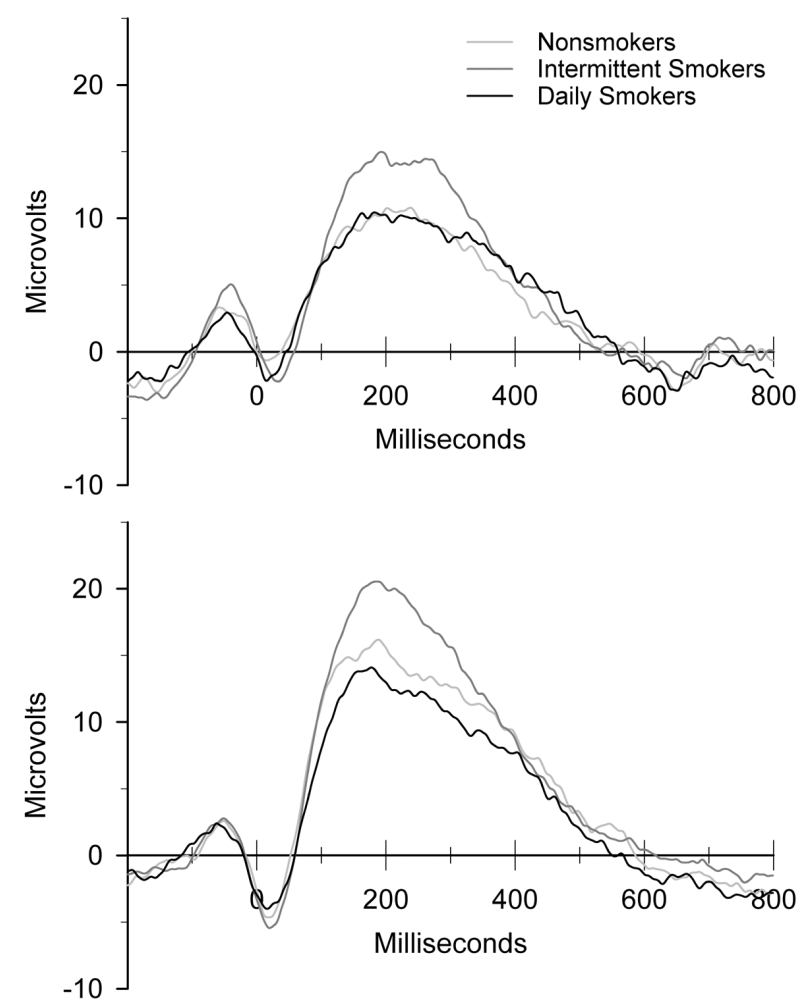

Figure 4.

Response-locked grand averages of ERP waveforms during error trials of the Eriksen Flanker Task (top) and Go/No-go Continuous Performance Task (bottom) for nonsmokers (light gray line), intermittent smokers (dark gray line), and daily smokers (black line) at the $\mathrm{Cz}$ electrode site. 
A. Ericksen Flanker Task

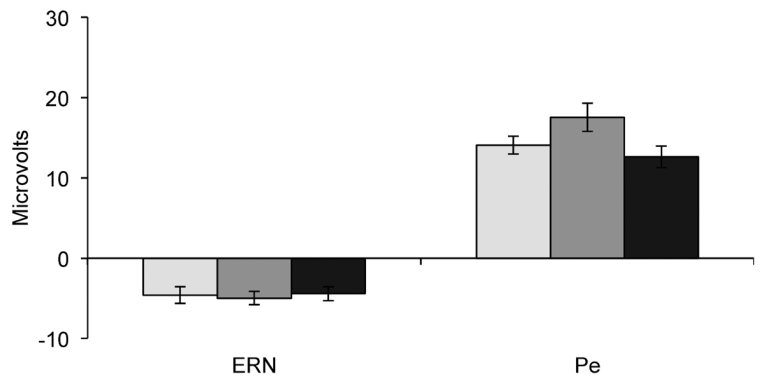

B. Go/No-go Continuous Performance Task

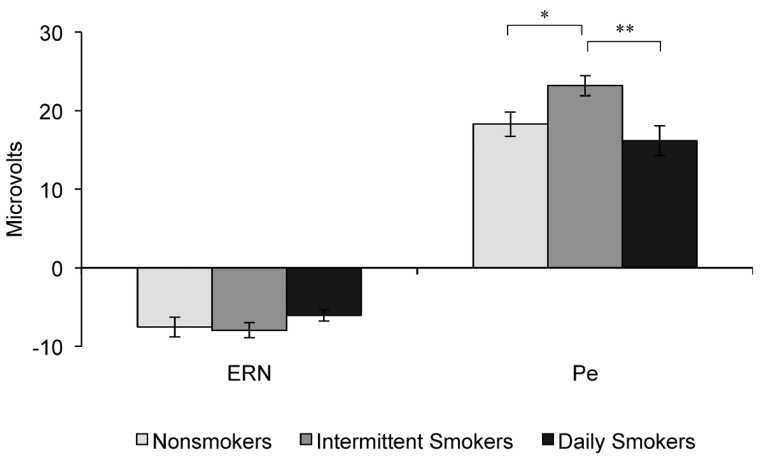

Figure 5.

Peak to peak measures of the ERN and Pe ERP components at the $\mathrm{Cz}$ electrode site during incorrect trials of the Eriksen Flanker (top) and Go/No-go Continuous Performance (bottom) tasks for nonsmokers (light gray), intermittent smokers (dark gray), and daily smokers (black). Error bars represent \pm 1 standard error. The following symbols represent significance: $* p<.05, * * p<.01$. 


\section{Table 1}

Demographics and Smoking Behavior.

\begin{tabular}{|c|c|c|c|c|c|}
\hline & Nonsmokers $(n=30)$ & $\begin{array}{l}\text { Intermittent Smokers ( } n \\
=\mathbf{3 1})\end{array}$ & Daily Smokers $(n=22)$ & Analysis & $p$ \\
\hline Sex Male n (\%) & $14(47 \%)$ & $12(39 \%)$ & $13(59 \%)$ & $X_{(2)}^{2}=2.15$ & .342 \\
\hline Age $M(S D)$ & $25.2(4.3)$ & $23.9(4.4)$ & $27.2(5.3)$ & $F_{(2,80)}=2.54$ & .085 \\
\hline Education (years) & $16.6(2.0)^{\mathrm{a}}$ & $15.8(1.6)$ & $14.8(1.6)^{\mathrm{b}}$ & $F_{(2,80)}=6.13$ & .003 \\
\hline Caffeine use any $n(\%)$ & $24(80 \%)$ & $28(90 \%)$ & $21(95 \%)$ & & \\
\hline Drinks / week $M(S D)$ & $6.4(6.4)$ & $9.1(6.3)$ & $11.0(6.5)$ & $F_{(2,80)}=2.90$ & .062 \\
\hline Alcohol use any $n(\%)$ & $22(73 \%)$ & $30(97 \%)$ & $22(100 \%)$ & & \\
\hline Drinks / night $M(S D)$ & $1.9(1.0)^{\mathrm{a}}$ & $3.1(1.5)^{\mathrm{b}}$ & $3.7(2.0)^{\mathrm{b}}$ & $F_{(2,71)}=8.28$ & .001 \\
\hline Nights / week $M(S D)$ & $1.6(1.0)$ & $1.9(1.0)$ & $1.8(0.9)$ & $F_{(2,71)}=.93$ & .401 \\
\hline Any past drug use $n(\%)$ & $5(17 \%)$ & $17(55 \%)$ & $11(50 \%)$ & $X^{2}{ }_{(2)}=10.59$ & .005 \\
\hline Marijuana & $5(100 \%)$ & $17(100 \%)$ & $11(100 \%)$ & & \\
\hline Other & $0(0 \%)$ & $2(12 \%)$ & $4(36 \%)$ & & \\
\hline Anxiety/Depression history $n(\%)$ & $2(7 \%)$ & $8(26 \%)$ & $4(18 \%)$ & $X^{2}{ }_{(2)}=4.02$ & .134 \\
\hline \multicolumn{6}{|l|}{ Ethnicity $n(\%)$} \\
\hline Caucasian & $20(67 \%)$ & $24(77 \%)$ & $18(82 \%)$ & & \\
\hline Asian & $8(27 \%)$ & $5(16 \%)$ & $3(14 \%)$ & & \\
\hline Black & $2(7 \%)$ & $1(3 \%)$ & $1(5 \%)$ & & \\
\hline Biracial & $0(0 \%)$ & $1(3 \%)$ & $0(0 \%)$ & & \\
\hline \multicolumn{6}{|l|}{$\mathrm{CO} \operatorname{ppm} M(S D)$} \\
\hline Post & $2.0(0.8)^{\mathrm{a}}$ & $2.8(1.9)^{\mathrm{a}}$ & $14.9(8.8)^{\mathrm{b}}$ & $F_{(2,80)}=57.49$ & $<.001$ \\
\hline Pre & $2.3(1.4)^{\mathrm{a}}$ & $3.7(2.9)^{\mathrm{a}}$ & $16.8(10.8)^{\mathrm{b}}$ & $F_{(2,80)}=45.66$ & $<.001$ \\
\hline Change score & $-0.3(0.8)^{\mathrm{a}}$ & $-0.9(1.3)$ & $-1.9(3.9)^{\mathrm{b}}$ & $F_{(2,80)}=3.36$ & .040 \\
\hline \multicolumn{6}{|l|}{ WSWS Craving $M(S D)$} \\
\hline Pre & $1.0(2.4)^{\mathrm{a}}$ & $7.0(6.5)^{\mathrm{b}}$ & $11.5(7.5)^{\mathrm{c}}$ & $F_{(2,80)}=22.20$ & $<.001$ \\
\hline Post & $0.8(2.0)^{\mathrm{a}}$ & $6.3(6.1)^{\mathrm{b}}$ & $15.0(7.3)^{\mathrm{c}}$ & $F_{(2,80)}=43.56$ & $<.001$ \\
\hline Change score & $-0.2(1.7)^{\mathrm{a}}$ & $-0.7(3.9)^{\mathrm{a}}$ & $-3.5(6.3)^{\mathrm{b}}$ & $F_{(2,80)}=7.41$ & .001 \\
\hline Age Initiation $M(S D)$ & & $18.1(1.7)^{\mathrm{a}}$ & $16.3(3.0)^{\mathrm{b}}$ & $F_{(1,51)}=7.88$ & .007 \\
\hline Years Smoked & & $5.6(4.4)^{\mathrm{a}}$ & $9.4(6.4)^{\mathrm{b}}$ & $F_{(1,51)}=6.69$ & .013 \\
\hline NDSS Total Score & & $-2.6(0.7)^{\mathrm{a}}$ & $-0.1(0.8)^{\mathrm{b}}$ & $F_{(1,51)}=89.70$ & $<.001$ \\
\hline FTND Total Score & & $0.5(0.9)^{\mathrm{a}}$ & $5.4(1.3)^{\mathrm{b}}$ & $F_{(1,51)}=272.52$ & $<.001$ \\
\hline 1. Cigarettes/Day & & $3.6(1.6)^{\mathrm{a}}$ & $16.1(6.1)^{b}$ & $F_{(1,51)}=119.07$ & $<.001$ \\
\hline 2. Smoke within 5 min & & $0 \%$ & $32 \%$ & & \\
\hline Smoke 5-30 min & & $3 \%$ & $64 \%$ & & \\
\hline Smoke $>30 \mathrm{~min}$ & & $97 \%$ & $5 \%$ & & \\
\hline 3. Hate to give up first cig & & $13 \%$ & $68 \%$ & & \\
\hline Hate to give up other cig & & $87 \%$ & $32 \%$ & & \\
\hline Attempted to quit smoking & & $48 \%$ & $95 \%$ & & \\
\hline
\end{tabular}

Clin Neurophysiol. Author manuscript; available in PMC 2015 July 01. 
Note. Means with different superscripted letters are significantly different, $p<.05$. Quantity of caffeine per caffeinated drink was not measured. Alcohol use data from one ITS is missing. Caffeine and alcohol use analysis included only those who used the substances. Drug use history refers to reported past use, which does not qualify as abuse or dependence under DSM-IV. Anxiety/Depression history refers to self-reported past episodes of anxiety or major depression. WSWS $=$ Wisconsin Smoking Withdrawal Scale revised; FTND $=$ Fagerstrom Test for Nicotine Dependence; NDSS = Nicotine Dependence Syndrome Scale. Cigarettes per day ranged from 2 to 10 for ITS and from 5 to 25 for Daily Smokers. 


\section{Table 2}

Analysis of ERP measures for the behavioral control tasks.

Nonsmokers Intermittent Smokers Daily Smokers Analysis $\quad p \quad$ Partial $\eta^{2}$

\begin{tabular}{ccccccc}
\hline \multicolumn{2}{l}{ Eriksen Flanker Task } & & & & & \\
\# Error Trials & $35(20)$ & $28(17)$ & $28(14)$ & $F_{(2,61)}=1.440$ & .244 & - \\
ERN Latency & $21.4(25.0)$ & $33.0(19.6)^{\mathrm{a}}$ & $13.9(25.6)^{\mathrm{b}}$ & $F_{(2,67)}=3.949$ & .024 & .105 \\
ERN Voltage & $-4.6(5.1)$ & $-5.0(4.1)$ & $-4.4(4.4)$ & $F_{(2,67)}=0.100$ & .905 & - \\
Pe Latency & $195.1(48.4)$ & $188.5(42.8)$ & $183.1(42.5)$ & $F_{(2,67)}=0.406$ & .668 & - \\
Pe Voltage & $14.1(5.5)$ & $17.5(8.7)$ & $12.6(6.1)$ & $F_{(2,67)}=3.082$ & .052 & .084 \\
Go/No-go Continuous Performance Task & & & & & \\
\# Error Trials & $30(16)$ & $30(14)$ & $30(10)$ & $F_{(2,72)}=0.002$ & .998 & - \\
ERN Latency & $12.7(21.9)$ & $19.2(15.9)$ & $19.1(16.1)$ & $F_{(2,72)}=1.067$ & .349 & - \\
ERN Voltage & $-7.5(6.3)$ & $-7.9(5.2)$ & $-6.1(3.3)$ & $F_{(2,72)}=0.836$ & .438 \\
Pe Latency & $186.3(46.7)$ & $184.8(40.8)$ & $179.9(44.0)$ & $F_{(2,72)}=0.132$ & .876 \\
Pe Voltage & $18.3(8.0)$ & $23.2(6.8)^{\mathrm{a}}$ & $16.2(8.2)^{\mathrm{b}}$ & $F_{(2,72)}=5.416$ & .006 & -131 \\
\hline
\end{tabular}

Note. ERN analyses used the FCz electrode site and Pe analyses used the Cz electrode site. Values represent $M(S D)$. Means with different superscripted letters are significantly different, $p<.05$. 
Table 3

Performance on inhibitory control measures.

\begin{tabular}{|c|c|c|c|}
\hline & Nonsmokers & Intermittent Smokers & Daily Smokers \\
\hline \multicolumn{4}{|l|}{ Eriksen Flanker Task } \\
\hline Congruent RT & $352.6(59.1)$ & $342.4(38.1)$ & $361.7(51.6)$ \\
\hline Incongruent $\mathrm{RT}$ & $384.7(69.7)$ & $372.7(38.3)$ & $391.5(54.0)$ \\
\hline \# Congruent errors & $10.0(8.5)$ & $6.3(5.9)$ & $7.9(4.8)$ \\
\hline \#Incongruent errors & $22.9(15.1)$ & $19.8(14.0)$ & $20.8(9.8)$ \\
\hline Post-error slowing (ms) & $50.8(32.9)$ & $63.6(43.9)$ & $65.4(45.9)$ \\
\hline \multicolumn{4}{|c|}{ Go/No-go Continuous Performance Task } \\
\hline Frequent RT & $239.3(26.6)$ & $230.1(39.3)$ & $250.2(43.0)$ \\
\hline Rare RT & $286.9(56.7)$ & $275.1(51.7)$ & $291.5(46.4)$ \\
\hline \# Frequent errors & $5.2(4.8)$ & $4.9(3.9)$ & $6.4(5.4)$ \\
\hline \# Rare errors & $24.1(14.7)$ & $25.2(12.4)$ & $24.5(8.3)$ \\
\hline Post-error slowing (ms) & $37.9(34.9)$ & $29.9(25.1)$ & $36.0(36.3)$ \\
\hline
\end{tabular}

Note. Values Represent $M(S D)$. Groups did not differ on behavioral performance. RT $=$ Response Time. 